\title{
Erratum to: Weather noise leading to EI Niño diversity in an ocean general circulation model
}

\author{
Jong-Won Lee ${ }^{1} \cdot$ Sang-Wook Yeh $^{1}{ }^{\mathbb{D}} \cdot$ Hyun-Su Jo ${ }^{1}$
}

Published online: 29 March 2017

(C) Springer-Verlag Berlin Heidelberg 2017

\section{Erratum to: Clim Dyn DOI 10.1007/s00382-016-3438-3}

The acknowledgment text has been missed out in the original publication of the article. The acknowledgment should read as given below:
Acknowledgements This work is supported by the Korea Meteorological Administration Research and Development Program under Grant KMIPA2015-1042.

The online version of the original article can be found under doi:10.1007/s00382-016-3438-3.

Sang-Wook Yeh

swyeh@hanyang.ac.kr

1 Department of Marine Sciences and Convergent Technology, Hanyang University, ERICA, Ansan, Republic of Korea 